\title{
Throttling Ranting Rhetoric and Rumor Run Amok
}

\author{
(Another in our series of interviews with S\&T policy consultant, Dr. Science I.M. Sage)
}

\begin{abstract}
MRS Bulletin: Dr. Sage, it's been some time since last we chatted. In the interim some sensational developments in our nation's capital, your own stomping ground, have distracted the public from many more boring but still worthwhile programs, not the least of which is the fate of federal $R \& D$ funding. Are you concerned?
\end{abstract}

Prof. Science I.M. Sage: Yes and no. It's been fascinating, hasn't it? There is so much to be learned from this phenomenon, it's hard to know just where to start. It is true that our special interest area is below most radars at the moment, but it fared fairly well in the final hours of the legislative session. Perhaps it is best at this juncture for it and us to remain invisible for a while. We could thereby avoid being accused of complicity in the recent distractions of the body politic from the more significant issues of the day.

MRSB: It's reassuring to hear that you are sanguine about our field's fiscal future, but what part could we possibly have played in those other political and scandalous machinations?

Dr. S.S.: History teaches us that when the public is looking to blame somebody for something, they lump the inventors of the tools in with their evil users. Simply guilt by association. You see we technologists created the tools that instantaneously broadcast every last tidbit of rumor, gossip, and perhaps even some actual information. Did we supply a users' manual that warns against saturation bombing of the populace with largely unauthenticated data that overwhelms any attempt to intermediate? Were critiques of fact and veracity protected from being simply swamped? These miraculous tools of ours that could bring us closer to direct democracy have instead, largely because of the instantaneity, brought us to a sort of media-based mob mentality. We obviously misguidedly assumed that everyone would use these "weapons of mass communications" as we would.

MRSB: That's a lot to think about. Our list of those to blame was lengthening, but we hadn't yet added our own names. Where did we go wrong?

Dr. S.S.: Although almost all of us are human with the usual foibles that implies, there are symptoms of civility in science. Our discourse relies on mutually accepted standards. We insist on citing retrievable sources. We demand that all terms be defined precisely. We expect all underlying assumptions to be revealed. We subject reports to intense scrutiny of fact and tests of reproducibility. We are happy to field the most skeptical assaults on our conclusions because our common goal is truth and our joint lexicon precludes dissembling. For example, when reading a journal article, have you ever had to worry about what all the meanings of " $R$ " are? Of course not. If there's an $R$ in the article, the author tells you if it's the gas constant, a radius, a spatial coordinate, an electrical resistance, a reflectivity, or a general relativistic tensor. No guess work there! We are expected to think out of the box and to apply creative license in our work. However, we are granted no poetic license in our communications. Ambiguity is our enemy. It was naive to think that in a larger societal setting, such deliberative care would obtain.

MRSB: Is it entirely fair to compare scientific discourse with public dialogue or monologue as the case may be? The former is a well-honed tool of our trade, whereas the latter simply satisfies the public's right to know. In any case, is not the genie out of the bottle, so to speak? What could we possibly do now to remediate the relentless rhetoric?

Dr. S.S.: I've often heard this cliche, "the public's right to know." Is that one in the Bill of Rights? I guess if the public is paying for something, it should receive timely progress reports. There is also the Freedom of Information Act that presumes someone who cares requests information and is then entitled to get it. Those kinds of communications resemble more our deliberative refereed style than they do gushes of minimal signal-to-noise spin, counter spin, filler (measured in time or column inches), hyperbole, and highly placed leakage. The public needs to exercise its right not to know if it doesn't want to. Or better put, its right not to "hear" when hearing does not lead to knowing. As long as that genie is out of the bottle, we should put it to work to fix this mess.

Careful analysis of the process, by yours truly of course, shows that what we have, to borrow a phrase from the gridiron, is an "end-run" problem. We have allowed the fast unmediated channels to feverishly circumvent those yoked by editorial judgement and fear. Then, the "quality" channels, seeing they're being scooped, skip several self-regulating steps and rush in to compound the problem. There's a lot of positive feedback in this loop. The best the reputable outlets can do to preserve a semblance of self-respect is to cite the unregulated channel as their source-a vicious circularity that lends the latter unwarranted credibility.

MRSB: That's a very astute analysis, but we ask again, what can be done?

Dr. S.S.: It's too late to take a page from those scientific journals that require reports of new developments be embargoed against publication in the popular press until after they have appeared in refereed form. It's also naive to think all breaking news could be subjected to the same restrictions as are election reports of trends in balloting before all the polls close. So the only solution left, consistent with both freedom of speech and our government's duty to protect us (even from ourselves), is a warning label. If we can put V-chips in TVs and send cookies and applets to PCs, then we can instruct them to look for an authenticator in a transmission that confirms the content has been multiply reviewed and blessed by media monitors whom we elect through editors we respect. This is not cen-. sorship, because we don't interdict the message or even delete a comma. At least 128-bit encryption would be required because purveyors of rubbish are smart people who would also have no qualms about hacking through our defenses.

If the message authentication step fails, then our screens would display a warning label such as, "Warning! Reading unauthenticated information may be hazardous to your intellect and ultimately to the fabric of our democracy-but by all means, go ahead at your own risk." A bit wordy, but I'm sure there's a poet regulator out there who can come up with a more succinct and * pithy version.

MRSB: Sounds like a brilliant scheme. Thanks so much for sharing your thoughts with us. You once again have authenticated our confidence in your savvy insights and ingenuity. As a not-quite news magazine of sorts, the Bulletin may even launch a trial balloon on your behalf to see if this concept flies with the public. Of course, we are only a relatively slow monthly. And, of course, we couldn't even hint at an endorsement of this idea before fully vetting it against the public's pulse. So, we'll just e-mail it, unattributed, to one of those internet outlets who can get it out lickety-split.

As reported by E.N. KAUFMANN 